\title{
Reverse and pull-away engines for the carrier rocket sustainer
}

\author{
Michael Yu. Alies ${ }^{1}$, Irec A. Solovatov ${ }^{2}$, and Nicholas W. Mitiukov ${ }^{1,2,3, *}$ \\ ${ }^{1}$ Udmurt Federal Research Center of the Ural Branch of the RAS, 426067 Izhevsk, Russia \\ ${ }^{2}$ Kalashnikov Izhevsk State Technical University, 426000 Izhevsk, Russia \\ ${ }^{3}$ International Network Center for Fundamental and Applied Research, 20036 Washington, USA
}

\begin{abstract}
The work on the parameters of the engines for pulling away the spent rocket stage to the restricted zone is conducted with the use of the sustainer engine specially calculated for the present investigation. It is shown that a special block of engines having the functions of reverse and pull away can be the most effective solution of the problem. Depending on the aim and launch site and the location of the restricted zone the best variant is the mounting of the units of small special-purpose engines.
\end{abstract}

\section{Introduction}

The fall of spent boost stages of rockets usually takes place in sparsely populated areas. However, at present the zones for falling spent stages are decreasing due to the expansion of economic activity. In this connection, the launch of rockets without special devices for pulling away spent stages to the restricted zones will probably become impossible in the nearest future [1].

The sustainer rocket engines of the first stage are optimized for the purpose of obtaining the desired speed of payload and delivering it to the destination point. After the sustainer rocket engine separation from the carrier of the subsequent stages, the spent rocket stage usually moves away along the trajectory resulting due to its previous operation. At present, there is only one an additional requirement - to pull the separated stage away from the launch site in the case of emergency or off-normal situation [2].

In the present investigation, a specially designed first-stage sustainer engine was used having thrust of $500 \mathrm{kH}$, initial mass of 12 tons, final mass of 4 tons (including the mass of the spent first stage and the initial masses of the subsequent stages), pitch angle of $48^{\circ}$ at the end of operation, the height of $27 \mathrm{~km}$ at the moment of separation and the speed of $2400 \mathrm{~m} / \mathrm{s}$.

\section{Determination of the parameters of the pull-away engine}

Firstly, it is necessary to select the parameters of the pull-away engine which will provide the optimal thrust-to-weight ratio. It is necessary to find out what is more advantageous: the

\footnotetext{
* Corresponding author: nico02@mail.ru
} 
increase of the thrust or the time of operation. For the test calculations, a case was taken when for the same mass of fuel the reverse engine had the thrust of $8 \mathrm{kH}$ and $80 \mathrm{kH}$. When reverse was absent, the flight range of the spent stage was $664 \mathrm{~km}$. When the thrust of the reverse engine was $80 \mathrm{kH}$, the flight range was $427 \mathrm{~km}$ and at the thrust of $8 \mathrm{kH}$ it was 444 $\mathrm{km}$. Thus, the short-time and powerful impulse seems to be more effective.

Secondly, it is necessary to calculate the optimal thrust angle for the pull-away engine. In this case the thrust angle was increased with the step of $10^{\circ}$ and the trajectory was calculated which allowed to determine the distance of the spent stage falling. The thrust vector angle of the pull-away engine was calculated upward from the longitudinal stage axis. Thus, $0^{\circ}$ is the direction coinciding with the longitudinal axis and speed vector (in this case, the angle of attack was taken equal to zero), $90^{\circ}$ is the upward direction perpendicular to the longitudinal axis, $180^{\circ}$ is the direction along the axis of symmetry opposite to the vector of speed. The plot of the dependence of the distance to the stage falling point on the thrust vector angle is shown in Fig.1.

As indicated in Fig.1, when the thrust angle of the reverse engine coincides with the thrust angle of the sustainer engine, the further boost of the stage takes place and its flight range increases to $789.9 \mathrm{~km}$. The average distance was $591.3 \mathrm{~km}$ mainly due to the increased mass of the spent stage because of the mounting of an additional engine onto it. The optimal angle of thrust vector appeared to be $170^{\circ}$; the distance was $429.6 \mathrm{~km}$. In this case the thrust of the reverse and pull-away engines was optimally directed both for deceleration of the stage and for the decrease of the pitch angle.

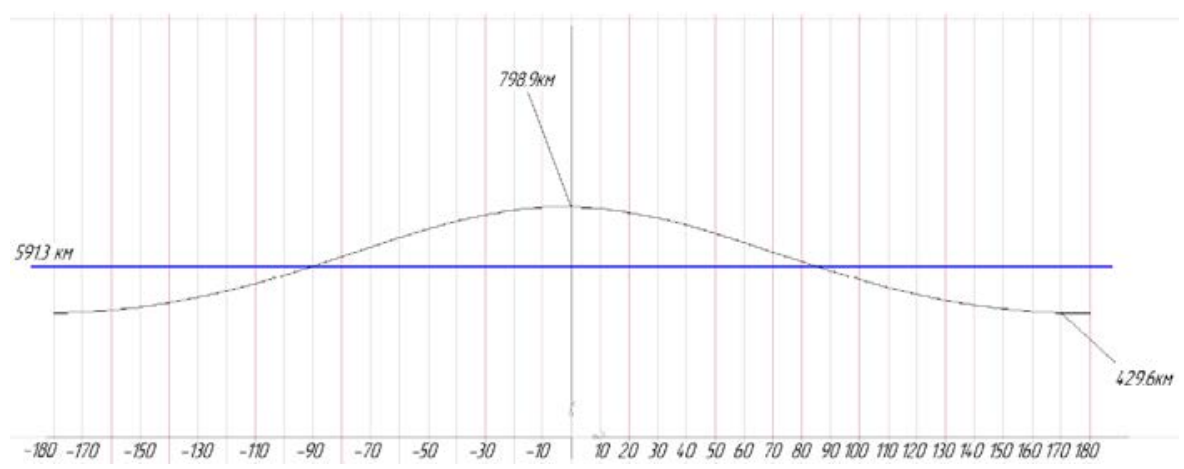

Fig. 1. Dependence of the flight range of the falling spent stage on the angle of the mounting of the reverse engine.



Fig. 2. The possible place for mounting the reverse and pull-away engine unit.

Usually the reverse engine combined with the sustainer engine is mounted on the forward head. In this case reverse engines obtain gas from the combustion-chamber assembly of a sustainer engine. In the case of the spent and jettisoned stage it is more advantageous to place the engines behind the centre of gravity to avoid the creation of disturbing moment. Thus, the only possible place for mounting the engine is the space near 
the diverging part of the nozzle, and the length of the reverse engine is determined by the length of the sustainer engine nozzle (Fig.2). At mounting, the reverse and pull-away engines and the lip form a "ring" the diameter of which is larger than the diameter of the sustainer nozzle exit section. Figure 3 presents the view of the reverse and pull-away engine block.



Fig. 3. The view of the reverse and pull-away engines.

The presented scheme has several advantages. Firstly, there is no need to mount all the engines at once; the scheme of mounting the engines can be determined by the flight task and the location coordinates of the restricted zone for falling spent blocks. Since the missiles having such caliber do not usually rotate during the flight, there is the possibility of correcting not only by the pitch angle but by the angle of yaw as well in order to pull the stage out from the guidance plane and to direct it to the firing area.

\section{Parameters of the falling of the spent stage equipped with the reverse and pull-away engines}

When the spent stage is jettisoned, its aerodynamic parameters are unstable, and the stage can obtain a certain angle of attack, which later influences the trajectory during entering dense atmospheric layers. For the calculation case it was taken that the stage can acquire the maximum angle of attack equal to $10^{\circ}$. Thus, the discrepancy in the flight ranges appears determining the sizes of the necessary restricted zone.

In the case without the reverse and pull-away engines when the mass of the engines is compensated by the mounted dead weight the flight range of the spent stage is in the range of $551-597 \mathrm{~km}$, i.e. the discrepancy is $46 \mathrm{~km}$ (about 8\%). When the reverse and pull-away engines are mounted in maximal engine configuration (the engines work only for reverse) the flight range of the spent stage is in the range of $436.5-468.5 \mathrm{~km}$, i.e. the discrepancy is 
$32 \mathrm{~km}$ (about 7\%). Thus, the use of reverse and pull-away engines allows to reduce the flight range of jettisoned stages which leads to the decrease of the relative and absolute sizes of the restricted zone.

\section{Conclusions}

The above example of the reversing and pulling away of the spent stage of the sustainer rocket engine shows:

1. The combination of the reverse and pull-away engines in one unit is most effective. The above example shows that the angle of the thrust vector equal to $170^{\circ}$ provides optimal combination of correcting the speed and pitch during the flight of the spent stage.

2. The best location for the mounting of the reverse and pull-away engines is the diverging part of the nozzle; it is advisable to use the engine in the form of the unit of engines which would be mounted individually depending on the flight task and the coordinates of the location of the restricted zone.

3. The use of the reverse and pull-away engines allows to decrease the discrepancy in the maximum flight ranges from $46 \mathrm{~km}$ to $32 \mathrm{~km}$ which leads to the significant decrease of the sizes of the restricted zone.

The article was prepared with the support of the Integrated Program for Basic Research Ural Branch of Russian Academy of Science, № 0427-2019-0019.

\section{References}

1. N. Mitiukov, T. Kasatkin, G. Samigullina, MATEC web of conferences. 129, 06007, (2017). DOI: 10.1051/matecconf/201712906007.

2. V.L. Solntsev, I.S. Radugin, V.A. Zadeba, Kosmicheskaya teknika i teknologii. 2, 2538 (2015). 